Article

\title{
Exploring Allometric Scaling Relations between Fractal Dimensions of Metro Networks and Economic, Environmental and Social Indicators: A Case Study of 26 Cities in China
}

\author{
Tian Lan ${ }^{1,2}$, Qian Peng ${ }^{1, *} \mathbb{C}$, Haoyu Wang ${ }^{2}$, Xinyu Gong ${ }^{1} \mathbb{D}$, Jing $\mathrm{Li}^{1}$ and Zhicheng Shi ${ }^{3}$ \\ 1 Department of Land Surveying and Geo-Informatics, The Hong Kong Polytechnic University, \\ Hong Kong 999077, China; tianlan@polyu.edu.hk (T.L.); jiajia.gong@connect.polyu.hk (X.G.); \\ jenne.li@connect.polyu.hk (J.L.) \\ 2 Faculty of Geosciences and Environmental Engineering, Southwest Jiaotong University, \\ Chengdu 611756, China; 2017114387@my.swjtu.edu.cn \\ 3 Research Institute for Smart Cities, School of Architecture and Urban Planning, Shenzhen University, \\ Shenzhen 518060, China; shizhicheng@szu.edu.cn \\ * Correspondence: q.peng@polyu.edu.hk
}

check for updates

Citation: Lan, T.; Peng, Q.; Wang, H.; Gong, X.; Li, J.; Shi, Z. Exploring Allometric Scaling Relations between Fractal Dimensions of Metro

Networks and Economic

Environmental and Social Indicators: A Case Study of 26 Cities in China. ISPRS Int. J. Geo-Inf. 2021, 10, 429. https://doi.org/10.3390/ijgi10070429

Academic Editors: Marco Helbich and Wolfgang Kainz

Received: 9 May 2021

Accepted: 19 June 2021

Published: 23 June 2021

Publisher's Note: MDPI stays neutral with regard to jurisdictional claims in published maps and institutional affiliations.

Copyright: (c) 2021 by the authors. Licensee MDPI, Basel, Switzerland This article is an open access article distributed under the terms and conditions of the Creative Commons Attribution (CC BY) license (https:// creativecommons.org/licenses/by/ $4.0 /)$
Abstract: Allometric scaling originates in biology, where it refers to scaling relations between the size of a body part and the size of the whole body when an organism grows. In cities, various allometric relations have also been discovered, such as those between the complexity of traffic networks and urban quantities. Metro networks are typical traffic networks in cities. However, whether allometric relations with metro networks exist is still uncertain. In this study, "fractal dimension" was employed as the complexity measure of metro networks, and potential allometric relations between fractal dimensions and urban indicators in 26 main cities in China were explored. It was found that fractal dimensions of metro networks had positive allometric relations with gross domestic product (GDP), population, particulate matter with a diameter less than 2.5 microns $\left(\mathrm{PM}_{2.5}\right)$, the road congestion index and the average price of second-hand housing (with Spearman's R of 0.789, 0.806, 0.273, 0.625 and 0.335 , respectively) but inverse allometric relations with sulfur dioxide $\left(\mathrm{SO}_{2}\right)$ and residential satisfaction (with Spearman's R of -0.270 and -0.419 , respectively). Such discoveries imply that allometric relations do exist with metro networks, which is helpful in deepening our understanding of how metro systems interact with urban quantities in the self-organized evolution of cities.

Keywords: fractal dimension; metro network; allometric scaling; socio-economic indicator

\section{Introduction}

Allometry (also called allometric growth or allometric scaling) is a concept that originally referred to scaling relations between the size of a body part and the size of the whole body when an organism grows [1,2]. Gradually, it was extended to refer to general biological scaling relationships for almost any co-varying biological measurements [3]. Allometric scaling was introduced into urban studies by Naroll and Von Bertalanffy [4]. Since then, various urban allometric analyses have been conducted to explore potential allometric relations in cities [5-8]. However, the scaling exponents of allometric relations cannot be well explained by the Euclidean dimension, which has led to the research in urban allometry falling into a dimensional dilemma [9]. Luckily, urban allometric studies re-attracted attention when fractal geometry theory was developed $[10,11]$. In the past two decades, more and more researchers have paid attention to the allometric phenomena of cities, and a field called "urban allometry" has gradually formed. The literature on urban allometry presents three primary themes: (1) exploration of potential allometric relations in cities, such as those between urban size and socio-economic quantities [12-24]; (2) development of novel metrics, rules or methods for better analysis of potential allometric relations [25-30]; and (3) explanations of the existence of urban allometric relations and 
analysis of how such relations affect socio-economic status [31-34]. All these studies are helpful for people to better understand, design and plan sustainable cities and, nowadays, allometric analysis has become an important tool for analyzing scale-free processes and patterns in geographical systems $[35,36]$.

Metro network systems are important subsystems of cities. Exploring and analyzing the potential allometric relations associated with the complexity of metro network systems is helpful to deepen our understanding of how metro systems interact with urban quantities in the self-organized evolution of cities. However, this topic has received little attention. We still do not know whether allometric relations exist for the complexity of metro networks or not. In the past decade, many urban metro operation systems have been constructed in China, which provides a solid basis for the analysis. In this study, the fractal dimension was employed as the complexity measure of metro networks, and the potential allometric relations between the fractal dimensions of 26 Chinese metro networks and various urban economic, environmental and social indicators were explored. The remainder of this article is organized as follows. Section 2 introduces the experimental data and fractal geometry theory. Section 3 analyzes the potential allometric relations between box-counting geometric fractal dimensions and urban indicators. Section 4 contains the discussion and conclusions.

\section{Data and Method}

\subsection{Study Area and Data Source}

China has constructed the largest number of metro operation systems in the world, and we collected data on 26 metro networks of main cities in China from Gaode map (see Figure 1). In addition, a variety of urban quantities in terms of the economy, the environment and society were acquired (see Table 1). More precisely, gross domestic product (GDP) and population data were collected from Baidu Library [37]; air pollution data, including data for particulate matter with a diameter less than 2.5 and 10 microns (i.e., $\mathrm{PM}_{2.5}$ and $\mathrm{PM}_{10}$ ), sulfur dioxide (chemical formula $\mathrm{SO}_{2}$ ), nitrogen dioxide (chemical formula $\mathrm{NO}_{2}$ ), carbon monoxide (chemical formula $\mathrm{CO}$ ) and ozone (chemical formula $\mathrm{O}_{3}$ ), were collected from an air quality historical data platform [38]; data on the average public information service score, average residential satisfaction score, average price of second-hand housing and the road traffic congestion index were collected from various survey reports [39-41].

\subsection{Fractal Theory}

- The development of fractal theory

The concept of a fractal originally refers to "a curve or pattern that includes a smaller curve or pattern which has exactly the same shape" [42]. These kinds of fractals are strictly self-similar, and they only exist in mathematical patterns, such as Koch Snow and the Sierpinski Triangle. Gradually, Mandelbrot $[10,11]$ extended the concept of fractals to refer to statistically self-similar patterns in nature (such as coastal lines), and a theory named "fractal geometry" was formed. Statistical self-similarity refers to a situation in which each portion of an object can be considered as a reduced-scale image of the whole object, and this self-similarity is described by a power-law relationship between the measurement scale and the number of scales needed to cover the object (i.e., the fractal dimension). It has been reported that the power law-based fractal dimension is "too strict for many geographic features" [43], and thus an alternative named the ht-index was recently proposed based on power law-like distributions [44-46]. In fact, both the power law exponent and the htindex can describe fractal properties of geographic features and phenomena. In this study, the research objects were metro networks which are usually described by the power law exponent-based fractal dimension, so "fractal dimension" hereafter refers to the exponent of the power law relationship. 


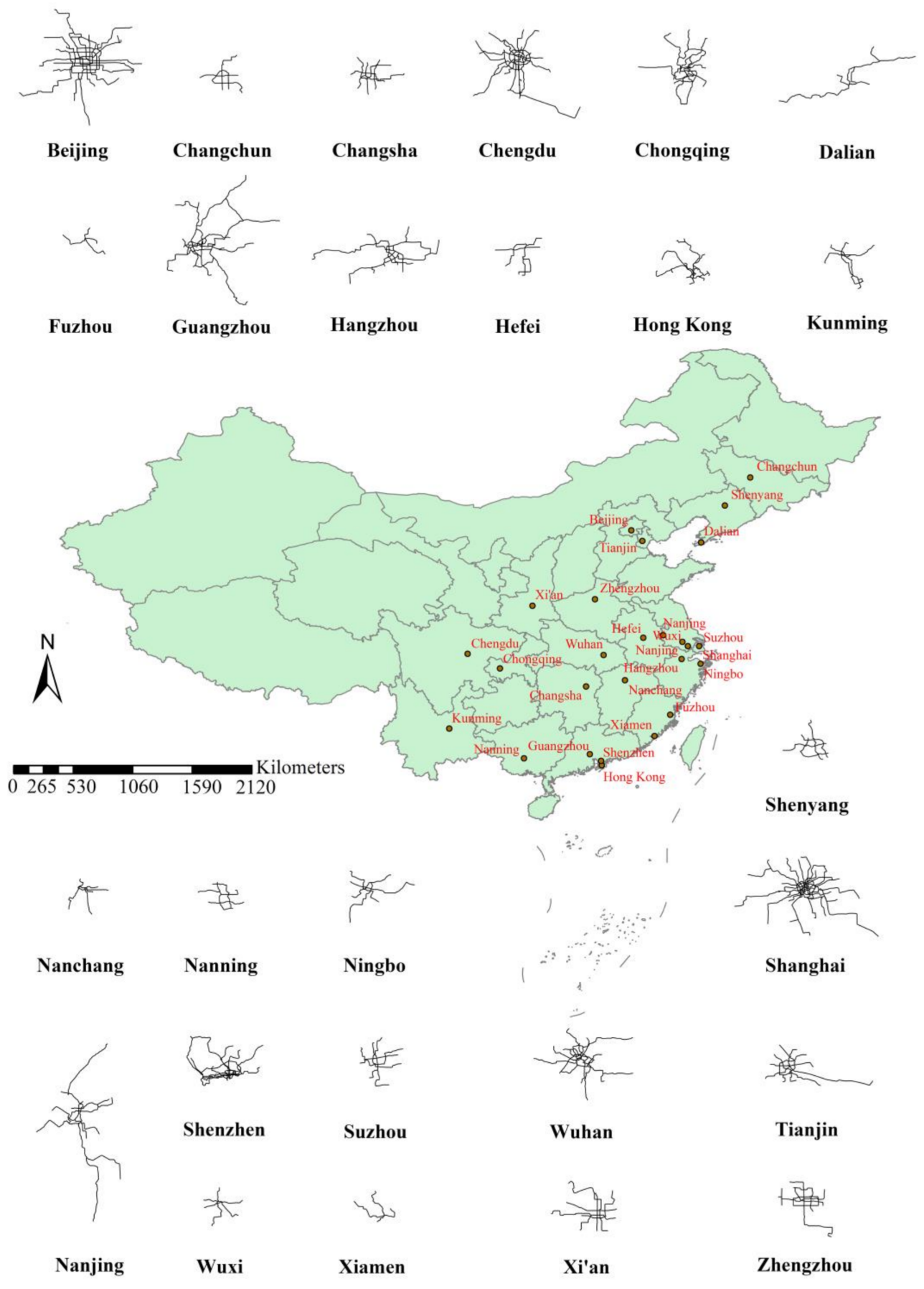

Note: all metro networks are at the same spatial scale.

Figure 1. Metro networks of 26 cities in China.

- The calculation of the fractal dimension

The research objects in this study were linear features (i.e., metro networks), and so we had to select appropriate methods to calculate the fractal dimension of linear features. It has been reported by Klinkenberg [47] that various methods are available, and these include divider methods [48], box-counting methods [49], spectral methods [50], variogram methods [51], area-based methods [52] and line-scaling methods [53]. 
Table 1. Acquired economic, environmental and social data of 26 cities.

\begin{tabular}{|c|c|c|c|c|c|c|c|c|c|c|c|c|}
\hline City & $\begin{array}{l}\text { GDP } \\
\text { (Billion } \\
\text { Yuan) }\end{array}$ & $\begin{array}{c}\text { Population } \\
\text { (Million) }\end{array}$ & $\begin{array}{c}\mathbf{P M}_{2.5} \\
\left(\mu \mathrm{g} / \mathrm{m}^{3}\right)\end{array}$ & $\begin{array}{c}\mathrm{PM}_{10} \\
\left(\mu \mathrm{g} / \mathrm{m}^{3}\right)\end{array}$ & $\begin{array}{c}\mathrm{SO}_{2} \\
\left(\mu \mathrm{g} / \mathrm{m}^{3}\right)\end{array}$ & $\begin{array}{c}\mathrm{NO}_{2} \\
\left(\mu \mathrm{g} / \mathrm{m}^{3}\right)\end{array}$ & $\underset{\left(\mu \mathrm{g} / \mathrm{m}^{3}\right)}{\mathrm{CO}}$ & $\begin{array}{c}\mathrm{O}_{3} \\
\left(\mu \mathrm{g} / \mathrm{m}^{3}\right)\end{array}$ & $\begin{array}{l}\text { Road Traffic } \\
\text { Congestion } \\
\text { Index }\end{array}$ & $\begin{array}{l}\text { Average Price of } \\
\text { Second-Hand } \\
\text { Housing (Yuan) }\end{array}$ & $\begin{array}{c}\text { Average } \\
\text { Residential } \\
\text { Satisfaction } \\
\text { Score }\end{array}$ & $\begin{array}{c}\text { Average Public } \\
\text { Information } \\
\text { Service Score }\end{array}$ \\
\hline Beijing & 3610.26 & 21.54 & 99.46 & 48.63 & 2.08 & 14.50 & 5.58 & 44.71 & 2.06 & 64,721 & 73.1 & 66.18 \\
\hline Shanghai & 3870.06 & 24.28 & 92.33 & 39.01 & 2.04 & 16.30 & 5.98 & 41.10 & 1.93 & 59,072 & 73.8 & 69.27 \\
\hline Guangzhou & 2501.91 & 15.31 & 75.48 & 35.89 & 2.96 & 16.29 & 6.20 & 39.20 & 1.89 & 39,851 & 75.9 & 63.70 \\
\hline Shenzhen & 2767.02 & 13.44 & 82.63 & 41.85 & 2.75 & 17.16 & 5.82 & 42.64 & 1.67 & 87,957 & 74.2 & 65.26 \\
\hline Wuhan & 1561.61 & 11.21 & 117.78 & 54.40 & 4.41 & 22.06 & 9.38 & 43.60 & 1.71 & 19,016 & 76.6 & 62.62 \\
\hline Tianjin & 1408.37 & 15.62 & 111.20 & 53.83 & 4.18 & 16.59 & 7.53 & 51.99 & 1.66 & 26,332 & 77.1 & 63.55 \\
\hline Hongkong & 2410.37 & 7.47 & 59.88 & 27.87 & 2.45 & 30.28 & 5.72 & 30.21 & null & null & null & null \\
\hline Chongqing & 2500.28 & 31.24 & 103.42 & 49.89 & 4.05 & 21.40 & 6.63 & 33.53 & 2.26 & 12,763 & 77.7 & 63.29 \\
\hline Hangzhou & 1610.58 & 10.36 & 103.03 & 54.63 & 3.05 & 23.16 & 6.95 & 44.12 & 1.76 & 33,862 & 77.9 & 71.48 \\
\hline Shenyang & 657.16 & 8.32 & 108.35 & 54.20 & 9.73 & 17.89 & 7.44 & 35.84 & 1.67 & 12,298 & 78.7 & 63.89 \\
\hline Dalian & 703.04 & 6.99 & 85.29 & 42.76 & 6.27 & 12.59 & 5.34 & 43.45 & 1.71 & 16,609 & 78.6 & 66.96 \\
\hline Chengdu & 1771.67 & 16.58 & 108.39 & 50.10 & 2.47 & 16.64 & 5.87 & 40.69 & 1.76 & 17449 & 76.5 & 63.94 \\
\hline Changchun & 663.80 & 8.57 & 99.17 & 59.20 & 5.83 & 17.92 & 6.64 & 39.61 & 1.79 & 10,030 & 75.4 & 66.85 \\
\hline Suzhou & 2017.05 & 10.75 & 105.42 & 49.18 & 3.72 & 19.50 & 6.91 & 52.37 & 1.56 & 22,052 & 77.6 & null \\
\hline Kunming & 673.38 & 6.95 & 66.36 & 30.61 & 3.64 & 8.67 & 4.97 & 35.09 & 1.86 & 14,394 & 74.8 & 65.65 \\
\hline Xi'an & 1002.04 & 10.20 & 122.47 & 71.77 & 3.62 & 22.62 & 6.42 & 39.34 & 1.99 & 15,849 & 78.3 & 59.88 \\
\hline Ningbo & 1240.87 & 8.54 & 85.23 & 40.64 & 4.47 & 18.45 & 5.97 & 43.66 & 1.39 & 24,465 & 78.3 & 70.78 \\
\hline Wuxi & 1237.05 & 6.59 & 99.67 & 50.01 & 3.34 & 17.56 & 7.61 & 46.62 & 1.53 & 17,707 & 79.8 & null \\
\hline Nanchang & 574.55 & 5.60 & 107.43 & 55.62 & 6.31 & 17.02 & 6.59 & 43.85 & 1.46 & 12,987 & 76.8 & 68.09 \\
\hline Fuzhou & 1002.00 & 7.80 & 76.48 & 41.29 & 2.32 & 11.65 & 6.86 & 54.89 & 1.60 & 27,103 & 78 & 65.64 \\
\hline Nanning & 472.63 & 7.34 & 81.60 & 39.96 & 3.88 & 10.98 & 6.29 & 33.49 & 1.48 & 13,102 & 75.7 & 64.62 \\
\hline Hefei & 1004.57 & 8.19 & 97.46 & 50.12 & 2.99 & 18.76 & 5.83 & 40.77 & 1.68 & 17,574 & 77.8 & 66.07 \\
\hline Xiamen & 638.40 & 4.29 & 58.26 & 29.12 & 2.88 & 7.45 & 3.90 & 46.46 & 1.60 & 49,803 & 77.9 & 71.30 \\
\hline
\end{tabular}

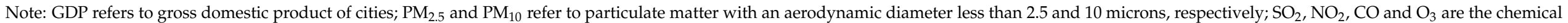

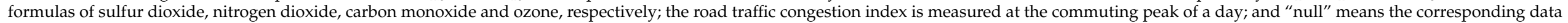
was inaccessible. 
Among these methods, box-counting methods have been widely used in analyzing the complexity of transport networks [54-56]. The box-counting fractal dimension is calculated by overlaying a grid of squares with size $l_{g}$ on the object to be measured and then counting the number of boxes $N_{g}$ that contain part of the object. By progressively reducing $l_{g}$, we can acquire a series of box numbers $N_{g}$. The whole calculation process of the box-counting method is shown in Figure 2, and the relationship between $N_{g}$ and $l_{g}$ is as follows:

$$
N_{g} \propto l_{g}^{-D_{g}}
$$

where $l_{g}$ refers to the side length of boxes; $N_{g}$ refers to the number of boxes covering the feature; and $D_{g}$ is the box-counting geometric fractal dimension [12].

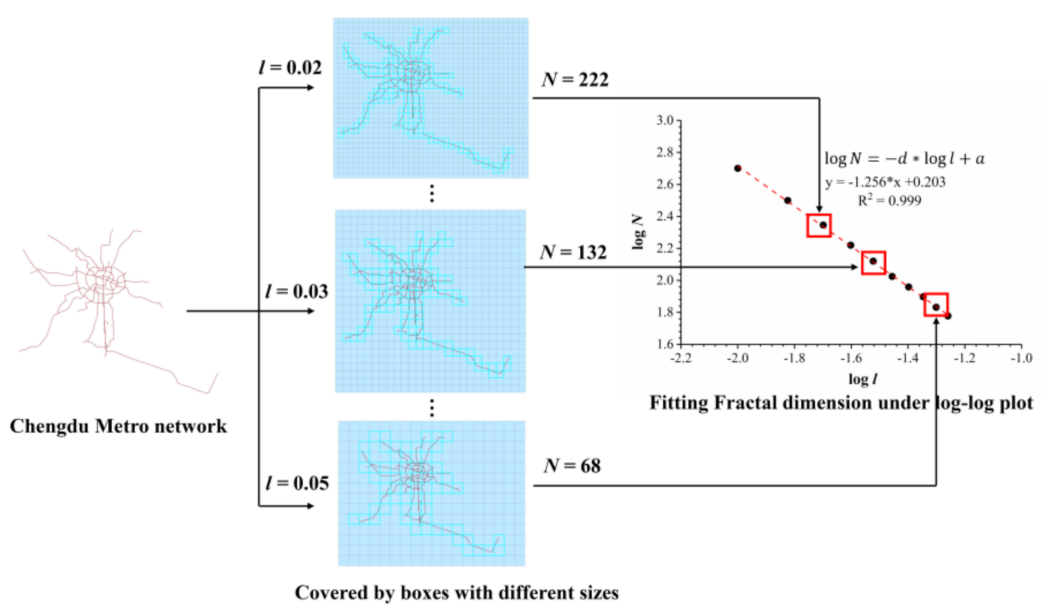

Figure 2. The whole process of calculating the box-counting fractal dimension.

We developed a computer program based on C\# to generate boxes with different sizes, and then the numbers of the covered boxes were counted using the "Select by Location" function of the professional GIS analysis software ArcGIS. Finally, fractal dimensions of various metro networks were calculated in the log-log plots by the data analysis software Origin. All the acquired fractal dimensions are shown in Table 2. All the values of the adjusted R-square in the calculation of the fractal dimensions were larger than 0.998 , which ensured that the acquired fractal dimensions are reliable. In the next section, the potential allometric relationships between fractal dimensions of 26 Chinese metro networks and various urban quantities in terms of economic, environmental and social indicators are examined.

Table 2. Fractal dimensions of 26 metro networks in China.

\begin{tabular}{|c|c|c|c|c|c|c|c|}
\hline No. & City & $\begin{array}{c}\text { Fractal } \\
\text { Dimension }\end{array}$ & $\begin{array}{c}\text { Adj. } \\
\text { R-Square }\end{array}$ & No. & City & $\begin{array}{c}\text { Fractal } \\
\text { Dimension }\end{array}$ & $\begin{array}{c}\text { Adj. } \\
\text { R-Square }\end{array}$ \\
\hline 1 & Beijing & 1.373 & 0.999 & 14 & Changchun & 1.043 & 0.999 \\
\hline 2 & Shanghai & 1.309 & 0.998 & 15 & Suzhou & 1.057 & 0.999 \\
\hline 3 & Guangzhou & 1.201 & 0.998 & 16 & Kunming & 1.068 & 0.999 \\
\hline 4 & Shenzhen & 1.272 & 0.998 & 17 & Xi'an & 1.135 & 0.998 \\
\hline 5 & Wuhan & 1.232 & 0.999 & 18 & Zhengzhou & 1.067 & 0.999 \\
\hline 6 & Tianjin & 1.173 & 0.999 & 19 & Changsha & 1.181 & 0.999 \\
\hline 7 & Nanjing & 1.135 & 0.999 & 20 & Ningbo & 1.125 & 0.999 \\
\hline 8 & $\begin{array}{l}\text { Hong } \\
\text { Kong }\end{array}$ & 1.124 & 0.999 & 21 & Wuxi & 1.035 & 0.999 \\
\hline 9 & Chongqing & 1.265 & 0.998 & 22 & Nanchang & 1.046 & 0.999 \\
\hline 10 & Hangzhou & 1.170 & 0.998 & 23 & Fuzhou & 1.025 & 0.999 \\
\hline 11 & Shenyang & 1.111 & 0.999 & 24 & Nanning & 1.024 & 0.999 \\
\hline 12 & Dalian & 1.061 & 0.999 & 25 & Hefei & 1.030 & 0.999 \\
\hline 13 & Chengdu & 1.256 & 0.999 & 26 & Xiamen & 1.031 & 0.999 \\
\hline
\end{tabular}




\section{Analyzing Allometric Scaling Relations between Fractal Dimension of Metro Networks and Urban Indicators}

\subsection{The Model and Types of Allometric Scaling}

Allometric scaling originally described how the rate of relative growth of an organ, $y$, is a constant fraction of the relative growth of the total organism, $x$ [6]. Such a relationship can be expressed as:

$$
\frac{d y}{d t} / y=\beta \frac{d x}{d t} / x
$$

After removing dt and integrating Formula (2), the following expression can be obtained:

$$
y=\alpha x^{\beta}
$$

where $\alpha$ and $\beta$ are constants. $\beta$ denotes the allometric scaling exponent and is used to classify the allometric relations as follows:

$\beta>1$ : positive allometric relation;

$\beta=1$ : isometric relation;

$0<\beta<1$ : negative allometric relation;

$\beta=0$ : independence;

$\beta<0$ : inverse allometric relation.

\subsection{Experimental Results: Box-Counting Fractal Dimensions vs. Urban Quantities}

Regression analysis was employed to explore potential allometric relationships between fractal dimensions of metro networks and urban indicators under log-log plots. Pearson's correlation coefficient (i.e., Pearson's R) is inappropriate in this analysis because the populations of the acquired data do not follow normal distributions. Spearman correlation coefficient (i.e., Spearman's R) is not strict with the data distributions, and hence such a correlation coefficient was employed here. In addition, $t$-tests were conducted to ensure the reliability of the analysis. The significance level is typically set at 0.05 , but we think this is too strict for potential relations. We have noticed that, in environmental studies, 0.2 is also acceptable as the value of the significance level [57]. As some dependent variables in our allometric analysis are environmental indexes, we set the significance level as 0.2 . In the allometric analysis, the independent variables were fractal dimensions of metro networks, while the dependent variables were 12 economic, environmental and social indicators (see Table 3). In terms of the $p$-value, it was found that seven dependent variables (GDP, population, $\mathrm{PM}_{2.5}, \mathrm{SO}_{2}$, road traffic congestion index, average price of second-hand housing and average residential satisfaction score) had strong allometric relations with fractal dimensions of metro networks with $p$-values smaller than 0.2 , while five other dependent variables had $p$-values larger than 0.2 . In terms of Spearman's $\mathrm{R}$, it was found that two different types of allometric scaling relation existed: fractal dimensions of metro networks had positive allometric relations with GDP, population, $\mathrm{PM}_{2.5}$, the road traffic congestion index and the average price of second-hand housing but inverse allometric relations with $\mathrm{SO}_{2}$ and the average residential satisfaction score. In the following part of this section, only those relations with $p$-values smaller than 0.2 are analyzed because allometric relations were reliable in these cases under the significance level of 0.2.

- Analysis of allometric relations between fractal dimensions of metro networks and urban size

Urban size was measured by GDP and population in this study. The fitting log-log figures of allometric relations between the fractal dimensions of metro networks and urban size are shown in Figure 3. It was found that strong positive allometric relations existed between them. The values of Spearman's $\mathrm{R}$ were 0.789 and 0.806 , respectively, with $p$-values of zero. Such results can be attributed to the fact that bigger cities have greater demand for larger metro networks. GDP provides the economic support for the construction of metro networks, while population reflects the demand of metro networks. For a city with a larger population and better economy, a more complex metro network is required to support 
the normal operation of the city. The fractal dimension of a metro network can reflect the urban size to some degree.

Table 3. The results of allometric analysis for 26 cities in China.

\begin{tabular}{cccc}
\hline $\begin{array}{c}\text { Independent } \\
\text { Variable }\end{array}$ & Dependent Variable & Spearman's R & $p$-Value \\
\hline & GDP & 0.789 & 0 \\
& Population & 0.806 & 0 \\
& $\mathrm{PM}_{2.5}$ concentration & 0.273 & 0.178 \\
$\mathrm{PM}_{10}$ concentration & 0.004 & 0.985 \\
Fractal dimensions & $\mathrm{NO}_{2}$ concentration & 0.185 & 0.367 \\
of metro networks & $\mathrm{SO}_{2}$ concentration & -0.270 & 0.183 \\
& $\mathrm{CO}$ concentration $\mathrm{O}_{3}$ concentration & -0.032 & 0.877 \\
& Road traffic congestion index & -0.172 & 0.401 \\
& Average price of second-hand housing & 0.625 & 0.001 \\
& Aeverage residential satisfaction score & 0.335 & 0.102 \\
& Aeverage public information service score & -0.419 & 0.037 \\
\hline
\end{tabular}

Note: GDP refers to gross domestic product; $\mathrm{PM}_{2.5}$ and $\mathrm{PM}_{10}$ refer to particulate matter with an aerodynamic diameter less than 2.5 and 10 microns, respectively; and $\mathrm{SO}_{2}, \mathrm{NO}_{2}, \mathrm{CO}$ and $\mathrm{O}_{3}$ are the chemical formulas of sulfur dioxide, nitrogen dioxide, carbon monoxide and ozone.
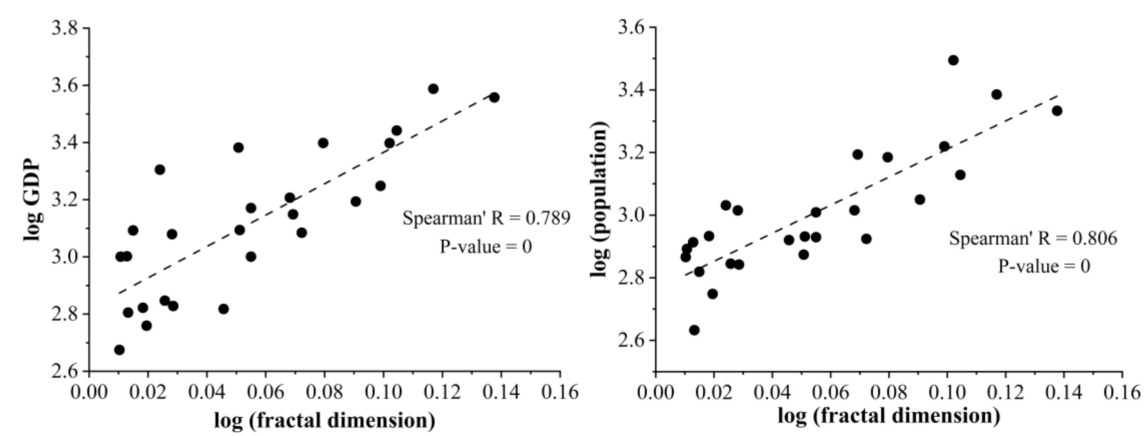

Figure 3. Fitting results between fractal dimensions of metro networks and urban size.

- Analysis of allometric relations between fractal dimension of metro networks and air pollution indexes

It was found that a positive allometric relation existed with $\mathrm{PM}_{2.5}$ concentration (with a Spearman's R and $p$-value of 0.273 and 0.178 , respectively), while an inverse one existed with $\mathrm{SO}_{2}$ concentration (with a Spearman's $\mathrm{R}$ and $p$-value of -0.270 and 0.183 , respectively). By contrast, no reliable allometric relations were found with $\mathrm{PM}_{10}, \mathrm{NO}_{2}, \mathrm{CO}$ and $\mathrm{O}_{3}$. In the following, the allometric relations with $\mathrm{PM}_{2.5}$ and $\mathrm{SO}_{2}$ concentration are analyzed and explained (see Figure 4).
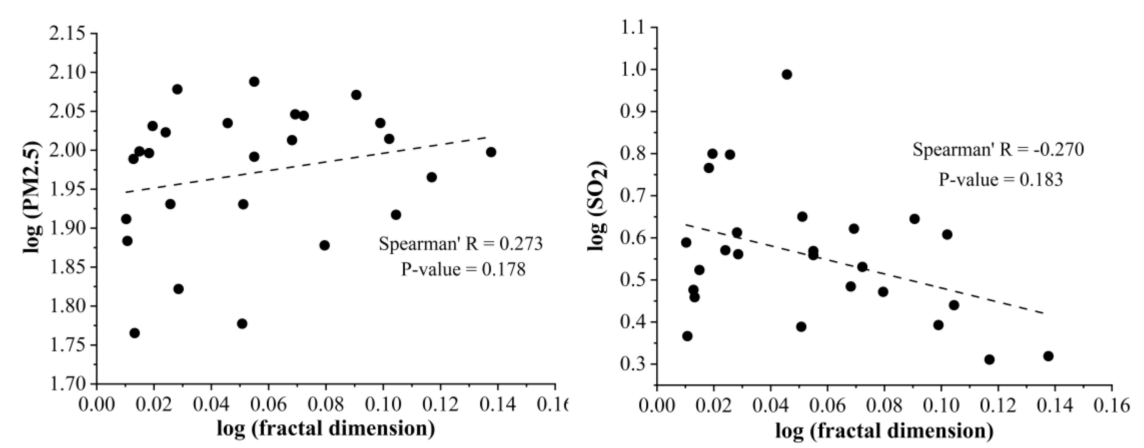

Figure 4. Fitting results between fractal dimensions of metro networks and air pollution indexes. 
In terms of $\mathrm{PM}_{2.5}$, we know that the major source of $\mathrm{PM}_{2.5}$ in cities is vehicle exhaust fumes/emissions. As we have found before, the fractal dimension of a metro network has strong positive allometric relations with urban population. This means that the larger the fractal dimension of a metro network is, the larger the corresponding urban population is. Generally, a larger population means a larger number of vehicles in a city, which leads to increasing vehicle exhaust emissions. Therefore, a positive allometric relation exists between fractal dimensions of metro networks and urban $\mathrm{PM}_{2.5}$ concentrations. In Chinese cities, the major source of $\mathrm{SO}_{2}$ is coal which is widely used in industrial production, thermal power and domestic consumption. In recent years, the Chinese government has formulated an air quality improvement policy, and the coal consumption of industrial production in big cities is strictly constrained [58]. By contrast, domestic coal consumption is hard to prohibit, especially in small cities, which leads to a situation in which small cities have higher $\mathrm{SO}_{2}$ concentrations than big cities. Therefore, an inverse relation exists between the fractal dimensions of metro networks and $\mathrm{SO}_{2}$ concentrations.

- Analysis of allometric relations between fractal dimensions of metro networks and socio-economic indicators

Fitting results with socio-economic indicators are shown in Figure 5. It was found that there were two positive allometric relations with the road traffic congestion index and the average price of second-hand housing (with Spearman's R of 0.625 and 0.335, respectively), while an inverse allometric relation was found with residential satisfaction (with Spearman's R of -0.419).
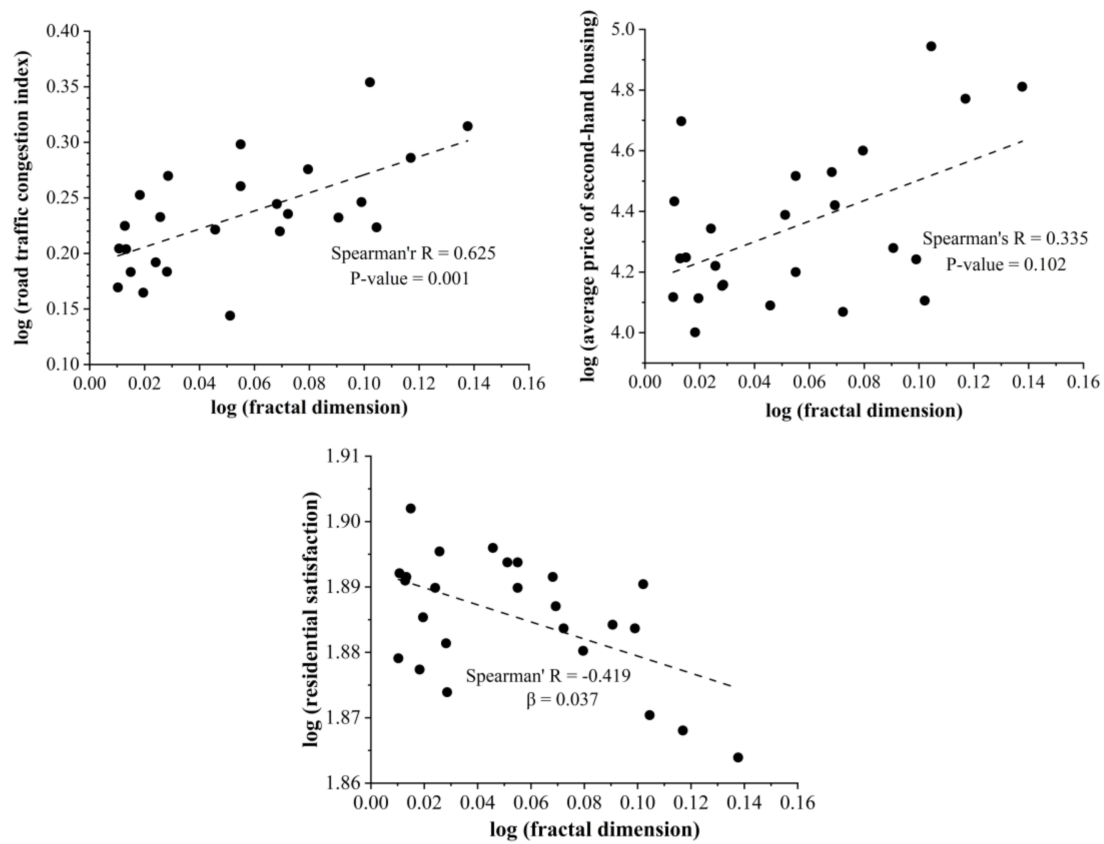

Figure 5. Fitting results between fractal dimensions of metro networks and socioeconomic indicators.

In practice, constructing metro networks can improve traffic accessibility and enable people to access destinations easily, which leads to the increase of housing prices around metro stations. Meanwhile, the high housing prices put more pressure on citizens in cities, and their residential satisfaction depends on the housing prices to some degree. As a result of various social and economic factors, positive and inverse allometric relations with the average price of second-hand housing and residential satisfaction have been formed. The increase of population size in cities brings traffic congestion. To reduce the road congestion level, metro operation systems are developed. We were surprised to find that cities with larger fractal dimensions of metro networks had higher levels of road congestion. This reflected the fact that the construction of metro networks may have limited effects on the 
reduction of road traffic congestion. In fact, road traffic congestion is affected by many factors, such as population and policy. More discussions about such relations are given in the following section.

\section{Discussion and Conclusions}

\subsection{Discussion}

Generally speaking, developing metro networks in cities is helpful to relieve road traffic pressure and to decrease vehicle exhaust emissions. This is because more people will choose to travel by metro instead of driving by themselves. However, in our study, the results seem to be different from the above statements (see the allometric relations with $\mathrm{PM}_{2.5}$ and the road traffic congestion index). To further explore how the development of metro networks affects vehicle exhaust emissions and road traffic congestion level in cities, we analyzed $\mathrm{PM}_{2.5}$ concentrations and road traffic congestion level in cities with similar population sizes (i.e., around 7 million) but different fractal dimensions in their metro networks (see Table 4 and Figure 6). We can see that, with similar population sizes, cities with larger fractal dimensions in their metro networks had lower $\mathrm{PM}_{2.5}$ levels. This supports the idea that the development of metro networks leads to the decreasing use of vehicles and then decreasing vehicle exhaust emissions. However, fractal dimensions of metro networks still have positive relations with the road traffic congestion index. This implies that metro networks have limited effects on the alleviation of road traffic pressure when compared with increasing population size.

Table 4. $\mathrm{PM}_{2.5}$ and road congestion indexes of cities with similar urban population sizes.

\begin{tabular}{cccccc}
\hline City & Population & $\begin{array}{c}\text { Fractal } \\
\text { Dimension }\end{array}$ & $\begin{array}{c}\mathbf{P M}_{\mathbf{2 . 5}} \\
\left(\boldsymbol{\mu g} / \mathbf{m}^{\mathbf{3}}\right)\end{array}$ & $\begin{array}{c}\mathbf{S O}_{\mathbf{2}} \\
\left(\boldsymbol{\mu} \mathbf{g} / \mathbf{m}^{\mathbf{3}}\right)\end{array}$ & $\begin{array}{c}\text { Road } \\
\text { Congestion }\end{array}$ \\
\hline Wuxi & & 1.035 & 99.67 & 3.34 & 1.525 \\
Kunming & Around & 1.068 & 66.4 & 3.64 & 1.861 \\
Dalian & 7 million & 1.061 & 85.3 & 6.27 & 1.709 \\
Nanning & & 1.024 & 81.6 & 3.88 & 1.477 \\
Hong Kong & & 1.124 & 59.9 & 2.45 & null \\
\hline
\end{tabular}
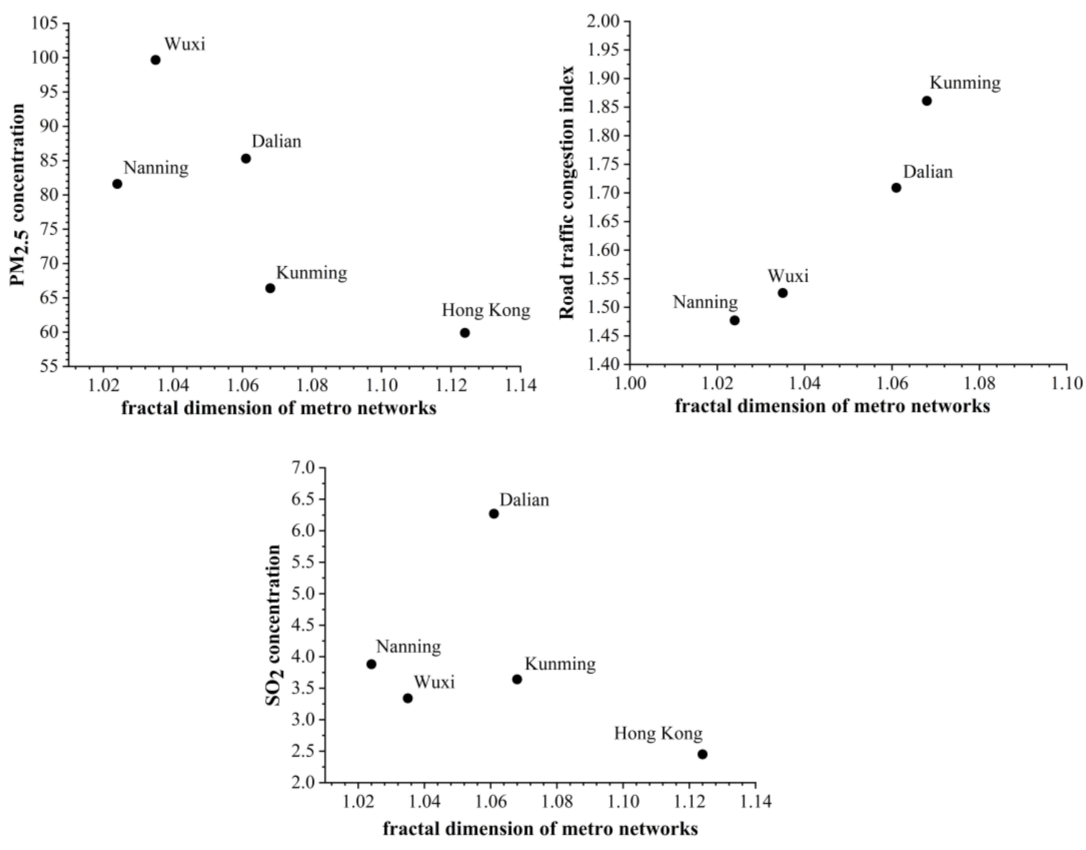

Figure 6. Trends in relations between fractal dimensions and urban quantities for cities with similar population sizes. 


\subsection{Conclusions}

Traffic networks are important subsystems in cities. As a typical traffic network, metro networks play critical roles in the normal operation of cities. Analyzing how metro networks interact with urban social, economic and environmental quantities is helpful for better planning, design and understanding of sustainable cities.

In this study, fractal dimensions were employed as a complexity measure of metro networks, and potential allometric relationships between fractal dimensions of metro networks and various urban quantities in 26 Chinese cities were explored. It was found that fractal dimensions of metro networks had strong positive allometric relations with urban size (i.e., population and gross domestic product) with Spearman's R of 0.806 and 0.789 , respectively. This indicates that fractal dimensions of metro networks are strongly related to urban size and can reflect urban size to some degree. In terms of air pollution indexes, it was found that fractal dimensions of metro networks had positive allometric relations with $\mathrm{PM}_{2.5}$ (with Spearman's $\mathrm{R}$ of 0.273 ) but inverse relations with $\mathrm{SO}_{2}$ (with Spearman's $\mathrm{R}$ of -0.270 ). When we analyzed these two air pollution indexes for cities with similar population sizes but different fractal dimensions, it was found that both demonstrated inverse relations with the fractal dimensions of metro networks. These results imply that the development of metro networks can reduce $\mathrm{PM}_{2.5}$ and $\mathrm{SO}_{2}$ concentrations to some degree, but these concentrations are also strongly affected by population size. In terms of socio-economic aspects, it was found that fractal dimensions of metro networks had positive allometric relations with the average price of secondhand housing but inverse relations with residential satisfaction. This indicates that the development of metro networks prompts increases in household prices and puts more pressure on citizens, which has negative effects on residential satisfaction. In addition, it was surprising to find that fractal dimensions of metro networks had positive allometric relations with the road traffic congestion index for both similar and different population sizes of cities. This implies that the development of metro networks has limited effects on the alleviation of road traffic congestion. In fact, road congestion is highly related to urban size. With these limited results, we can conclude that the fractal dimensions of metro networks have various allometric relations with urban social, environmental and economic quantities. These discoveries are helpful for deepening our understanding of how metro systems interact with urban quantities in the self-organized evolution of cities.

There were some limitations in this study. Firstly, urban social, environmental and economic quantities are affected by multiple factors. Only using one aspect of metro networks (i.e., the fractal dimension) to explain the interactive effects has limited effects. Secondly, the number of city samples was still too small. Studying allometric relations with a larger number of cities may lead to new discoveries.

Author Contributions: Conceptualization, Tian Lan; methodology, Tian Lan and Qian Peng; formal analysis, Qian Peng, Haoyu Wang and Xinyu Gong; data curation, Xinyu Gong, Jing Li and Zhicheng Shi; writing — original draft preparation, Tian Lan and Qian Peng; visualization, Haoyu Wang. All authors have read and agreed to the published version of the manuscript.

Funding: This research received no external funding.

Institutional Review Board Statement: Not applicable.

Informed Consent Statement: Not applicable.

Data Availability Statement: The data that support the findings of this study are openly available in "figshare" at http:/ / doi.org/10.6084/m9.figshare.14743053.

Acknowledgments: We thank Jicheng Wang at Sichuan Normal University for his helpful discussions and suggestions.

Conflicts of Interest: The authors declare no conflict of interest. 


\section{References}

1. Huxley, J. Problems of Relative Growth; Dial Press: New York, NY, USA, 1932.

2. Thompson, D.W. On Growth and Form; Cambridge University Press: Cambridge, UK, 1942.

3. Nordbeck, S. The Law of Allometric Growth. In Michigan Inter-University Community of Mathematical Geographers; Discussion Paper No. 7; University Microfilms: Ann Arbor, MI, USA, 1965.

4. Naroll, R.S.; Von Bertalanffy, L. The principle of allometry in biology and the social sciences. Gen. Syst. Yearb. 1956, 1 Pt II, 76-89.

5. Newling, B.E. Urban growth and spatial structure: Mathematical models and empirical evidence. Geogr. Rev. 1966, 213-225. [CrossRef]

6. Nordbeck, S. Urban allometric growth. Geogr. Ann. Series B Hum. Geogr. 1971, 53, 54-67. [CrossRef]

7. Bon, R. Allometry in the topologic structure of architectural spatial systems. Ekistics 1973, 36, $270-276$.

8. Woldenberg, M.J. An allometric analysis of urban land use in the United States. Ekistics 1973, 36, 282-290.

9. Chen, Y.G. The rise, fall, and revival process of allometric scaling analysis in urban studies. Geogr. Res. 2013, $32,1033-1045$.

10. Mandelbrot, B.B. How long is the coast of Britain? Statistical self-similarity and fractional dimension. Science 1967, 156, 636-638. [CrossRef] [PubMed]

11. Mandelbrot, B.B. The Fractal Geometry of Nature; Freeman: New York, NY, USA, 1982.

12. Bettencourt, L.M.; Lobo, J.; Helbing, D.; Kühnert, C.; West, G.B. Growth, innovation, scaling, and the pace of life in cities. Proc. Natl. Acad. Sci. USA 2007, 104, 7301-7306. [CrossRef] [PubMed]

13. Batty, M.; Carvalho, R.; Hudson-Smith, A.; Milton, R.; Smith, D.; Steadman, P. Scaling and allometry in the building geometries of Greater London. Eur. Phys. J. B Condens. Matter Complex Syst. 2008, 63, 303-314. [CrossRef]

14. Samaniego, H.; Moses, M.E. Cities as organisms: Allometric scaling of urban road networks. J. Transp. Land Use 2008, 1, 21-39. [CrossRef]

15. Alves, L.G.; Ribeiro, H.V.; Lenzi, E.K.; Mendes, R.S. Empirical analysis on the connection between power-law distributions and allometries for urban indicators. Phys. A Stat. Mech. Its Appl. 2014, 409, 175-182. [CrossRef]

16. Chen, Y.G. An allometric scaling relation based on logistic growth of cities. Chaos Solitons Fractals 2014, 65, 65-77. [CrossRef]

17. Bettencourt, L.M.; Lobo, J. Urban scaling in Europe. J. R. Soc. Interface 2016, 13, 20160005. [CrossRef]

18. Facchini, A.; Kennedy, C.; Stewart, I.; Mele, R. The energy metabolism of megacities. Appl. Energy 2017, 186, 86-95. [CrossRef]

19. Sarkar, S.; Phibbs, P.; Simpson, R.; Wasnik, S. The scaling of income distribution in Australia: Possible relationships between urban allometry, city size, and economic inequality. Environ. Plan. B Urban Anal. City Sci. 2018, 45, 603-622. [CrossRef]

20. Gudipudi, R.; Rybski, D.; Lüdeke, M.K.; Kropp, J.P. Urban emission scaling-Research insights and a way forward. Environ. Plan. B Urban Anal. City Sci. 2019, 46, 1678-1683. [CrossRef]

21. Gudipudi, R.; Rybski, D.; Lüdeke, M.K.; Zhou, B.; Liu, Z.; Kropp, J.P. The efficient, the intensive, and the productive: Insights from urban Kaya scaling. Appl. Energy 2019, 236, 155-162. [CrossRef]

22. Lan, T.; Li, Z.L.; Zhang, H. Urban Allometric Scaling Beneath Structural Fractality of Road Networks. Ann. Am. Assoc. Geogr. 2019, 109, 943-957. [CrossRef]

23. Sarkar, S. Urban scaling and the geographic concentration of inequalities by city size. Environ. Plan. B Urban Anal. City Sci. 2019, 46, 1627-1644. [CrossRef]

24. Akuraju, V.; Pradhan, P.; Haase, D.; Kropp, J.P.; Rybski, D. Relating SDG11 indicators and urban scaling-An exploratory study. Sustain. Cities Soc. 2020, 52, 101853. [CrossRef]

25. Chen, Y.G.; Jiang, S. An analytical process of the spatio-temporal evolution of urban systems based on allometric and fractal ideas. Chaos Solitons Fractals 2009, 39, 49-64. [CrossRef]

26. Alves, L.G.; Ribeiro, H.V.; Lenzi, E.K.; Mendes, R.S. Distance to the scaling law: A useful approach for unveiling relationships between crime and urban metrics. PLOS ONE 2013, 8, e69580.

27. Alves, L.G.; Mendes, R.S.; Lenzi, E.K.; Ribeiro, H.V. Scale-adjusted metrics for predicting the evolution of urban indicators and quantifying the performance of cities. PLOS ONE 2015, 10, e0134862. [CrossRef] [PubMed]

28. Chen, Y.G. Multi-scaling allometric analysis for urban and regional development. Phys. A Stat. Mech. Its Appl. 2017, 465, 673-689. [CrossRef]

29. Chen, Y.G.; Feng, J. A Hierarchical Allometric Scaling Analysis of Chinese Cities: 1991-2014. Discret. Dyn. Nat. Soc. 2017, 2017, 5243287. [CrossRef]

30. Li, R.; Dong, L.; Zhang, J.; Wang, X.; Wang, W.-X.; Di, Z.; Stanley, H.E. Simple spatial scaling rules behind complex cities. Nat. Commun. 2017, 8, 1841. [CrossRef] [PubMed]

31. Paulus, F.; Pumain, D.; Vacchiani-Marcuzzo, C.; Lobo, J. An evolutionary theory for interpreting urban scaling laws. Cybergeo Rev. Eur. Géogr. Eur. J. Geogr. 2006, 343, 1-20.

32. Bettencourt, L.M. The origins of scaling in cities. Science 2013, 340, 1438-1441. [CrossRef] [PubMed]

33. Gomez-Lievano, A.; Patterson-Lomba, O.; Hausmann, R. Explaining the prevalence, scaling and variance of urban phenomena. Nat. Hum. Behav. 2016, 1, 1-57. [CrossRef]

34. Khiali-Miab, A.; van Strien, M.J.; Axhausen, K.W.; Grêt-Regamey, A. Combining urban scaling and polycentricity to explain socio-economic status of urban regions. PLOS ONE 2019, 14, e0218022. [CrossRef] [PubMed]

35. Long, Y.; Chen, Y.G. Multifractal scaling analyses of urban street network structure: The cases of twelve megacities in China. PLoS ONE 2021, 16, e0246925. [CrossRef] 
36. Ma, D.; Guo, R.; Jing, Y.; Zheng, Y.; Zhao, Z.; Yang, J. Intra-Urban Scaling Properties Examined by Automatically Extracted City Hotspots from Street Data and Nighttime Light Imagery. Remote Sens. 2021, 13, 1322. [CrossRef]

37. Baidu Library. Population and GDP Data of Cities across the Country. Available online: https://wenku.baidu.com/view/0370a5 ad1cd9ad51f01dc281e53a580217fc5040.html (accessed on 8 June 2021).

38. The World Air Quality Project. Air Quality Historical Data Platform. Available online: https://aqicn.org/data-platform/register/ (accessed on 9 May 2021).

39. China Index Academy. Survey Report on Residential Satisfaction of Chinese Urban Residents. Available online: https: / /industry. fang.com/ (accessed on 9 May 2021).

40. Baidu Company. Baidu China Urban Transportation Report. Available online: https://jiaotong.baidu.com/cms/reports/traffic/ 2020annualtrafficreport/index.html (accessed on 9 May 2021).

41. China Pay Data. National House Price Ranking. Available online: http:// finance.eastmoney.com/a/202101021759304827.html (accessed on 12 June 2021).

42. Oxford Dictionary. The Definition of Fractal. Available online: https://www.oxfordlearnersdictionaries.com/definition/english/ fractal?q=fractal (accessed on 9 May 2021).

43. Jiang, B.; Yin, J. Ht-index for quantifying the fractal or scaling structure of geographic features. Ann. Assoc. Am. Geogr. 2014, 104, 530-540. [CrossRef]

44. Gao, P.C.; Liu, Z.; Tian, K.; Liu, G. Characterizing Traffic Conditions from the Perspective of Spatial-Temporal Heterogeneity. ISPRS Int. J. Geo Inf. 2016, 5, 34. [CrossRef]

45. Gao, P.C.; Liu, Z.; Xie, M.; Tian, K.; Liu, G. CRG index: A more sensitive ht-index for enabling dynamic views of geographic features. Prof. Geogr. 2016, 68, 533-545. [CrossRef]

46. Gao, P.C.; Liu, Z.; Liu, G.; Zhao, H.; Xie, X. Unified metrics for characterizing the fractal nature of geographic features. Ann. Am. Assoc. Geogr. 2017, 107, 1315-1331. [CrossRef]

47. Klinkenberg, B. A review of methods used to determine the fractal dimension of linear features. Math. Geol. 1994, 26, 23-46. [CrossRef]

48. Batty, M.; Longley, P.A. The fractal simulation of urban structure. Environ. Plan. A 1986, 18, 1143-1179. [CrossRef]

49. Shelberg, M.C.; Lam, N.; Moellering, H. Measuring the Fractal Dimensions of Surfaces; Defense Mapping Agency Aerospace Center: St Louis, MO, USA, 1983.

50. Power, W.L.; Tullis, T.E. Euclidean and fractal models for the description of rock surface roughness. J. Geophys. Res. Solid Earth 1991, 96, 415-424. [CrossRef]

51. Burrough, P. Fractal dimensions of landscapes and other environmental data. Nature 1981, 294, 240-242. [CrossRef]

52. Mandelbrot, B.B. Stochastic models for the Earth's relief, the shape and the fractal dimension of the coastlines, and the number-area rule for islands. Proc. Natl. Acad. Sci. USA 1975, 72, 3825-3828. [CrossRef]

53. Matsushita, M.; Ouchi, S. On the self-affinity of various curves. Phys. D Nonlinear Phenom. 1989, 38, 246-251. [CrossRef]

54. Benguigui, L. A fractal analysis of the public transportation system of Paris. Environ. Plan. A 1995, 27, 1147-1161. [CrossRef]

55. Lu, Y.; Tang, J. Fractal dimension of a transportation network and its relationship with urban growth: A study of the Dallas-Fort Worth area. Environ. Plan. B Plan. Des. 2004, 31, 895-911. [CrossRef]

56. Zhang, H.; Gao, P.; Lan, T.; Liu, C. Exploring the Structural Fractality of Urban Road Networks by Different Representations. Prof. Geogr. 2021, 1-15. [CrossRef]

57. Chmielewski, F.-M.; Rötzer, T. Response of tree phenology to climate change across Europe. Agric. For. Meteorol. 2001, 108, 101-112. [CrossRef]

58. Renmin University of China. Research on the Plan and Policy of Total Coal Con sumption Control in Chinese Cities. Available online: https: / / www.china5e.com/ (accessed on 9 May 2021). 